\title{
Understanding COVID-19 transmission, health impacts and mitigation: timely social distancing is the key
}

\author{
Satinder Kaur ${ }^{1} \cdot$ Hemant Bherwani ${ }^{2,3}$ (D) Sunil Gulia ${ }^{4} \cdot$ Ritesh Vijay $^{2} \cdot$ Rakesh Kumar $^{2}$
}

Received: 10 June 2020 / Accepted: 11 July 2020 / Published online: 18 July 2020

(c) Springer Nature B.V. 2020

\begin{abstract}
COVID-19 is a highly infectious disease caused by SARS-CoV-2, first identified in China and spread globally, resulting into pandemic. Transmission of virus takes place either directly through close contact with infected individual (symptomatic/asymptomatic) or indirectly by touching contaminated surfaces. Virus survives on the surfaces from few hours to days. It enters the human body through nose, eyes or mouth. Other sources of contamination are faeces, blood, food, water, semen etc. Parameters such as temperature/ relative humidity also play an important role in transmission. As the disease is evolving, so are the number of cases. Proper planning and restriction are helping in influencing the trajectory of the transmission. Various measures are undertaken to prevent infection such as maintaining hygiene, using facemasks, isolation/quarantine, social/physical distancing, in extreme cases lockdown (restricted movement except essential services) in hot spot areas or throughout the country. Countries that introduced various mitigation measures had experienced control in transmission of COVID-19. Python programming is conducted for change point analysis (CPA) using Bayesian probability approach for understanding the impact of restrictions and mitigation methods in terms of either increase or stagnation in number of COVID-19 cases for eight countries. From analysis it is concluded that countries which acted late in bringing in the social distancing measures are suffering in terms of high number of cases with USA, leading among eight countries analysed. The CPA week in comparison with date of lockdown and first reported case strongly correlates (Pearson's $r=-0.86$ to -0.97 ) to cases, cases per unit area and cases per unit population, indicating earlier the mitigation strategy, lesser the number of cases. The overall paper will help the decision makers in understanding the possible steps for mitigation, more so in developing countries where the fight against COVID-19 seems to have just begun.
\end{abstract}

Keywords COVID-19 $\cdot$ SARS-CoV-2 $\cdot$ Pandemic $\cdot$ COVID-19 health impacts $\cdot$ Social distancing $\cdot$ Change point analysis $\cdot$ Bayesian probability

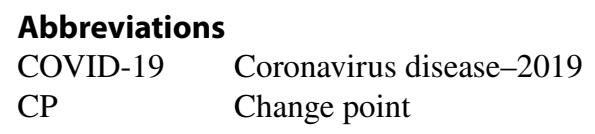

Hemant Bherwani

h.bherwani@neeri.res.in

Extended author information available on the last page of the article 


$\begin{array}{ll}\text { CPA } & \text { Change point analysis } \\ \mathrm{CP}_{\mathrm{w}} & \text { CP week } \\ \mathrm{CT} & \text { Computed tomography } \\ \mathrm{CW} & \text { Case weeks before lockdown } \\ \mathrm{D} & \text { Delta } \\ \mathrm{D}_{\mathrm{fr}} & \text { Date of first case reporting } \\ \mathrm{D}_{1} & \text { Lockdown date } \\ \text { PPE } & \text { Personal protective equipment } \\ \text { rRT-PCR } & \text { Real-time reverse transcription-polymerase chain reaction } \\ \text { SARS-CoV-2 } & \text { Severe acute respiratory syndrome CoronaVirus 2 }\end{array}$

\section{Introduction}

COVID-19 is caused by novel strain of virus SARS-CoV-2 emerged from China and now declared as pandemic due to its presence across the continents in more than 213 countries. Based on genetic analysis SARS-CoV-2 is grouped in a family Coronaviridae, genus Betacoronavirus and subgenus Sarbecovirus (Benvenuto et al. 2020; Lau et al. 2020; Lu et al. 2020). Coronaviruses are known to infect series of animals, birds, rodents, reptiles and humans (Ji et al. 2020). Similarly, SARS-CoV-2 is also zoonotic in nature by showing animal to human transmission. SARS-CoV-2 is reported to share $96 \%$ nucleotide identity with horseshoe bat (Rhinolophus affinis), suggesting it as a natural host (Andersen et al. 2020; Paraskevis et al. 2020). It is further assumed that SARS-CoV-2 moved from bats to an intermediate host Malayan pangolin (Manis javanica) sharing 91\% nucleotide identity and then to humans (Lam et al. 2020; Zhang et al. 2020a, b, c). The capability of coronaviruses for host switching demonstrates strong adaptive capacity, suggesting that there can be other possible intermediate hosts (Smith and Denison 2012). More elaborate research and studies are required to examine wide variety of animals as an intermediate host.

SARS-CoV-2 is deadly due to its high transmission and fatality rates (Carleton and Meng 2020). At present average fatality rate from COVID-19 is reported to be $3.4 \%$ (Rajgor et al. 2020). Structural modelling depicts that SARS-CoV-2 readily binds with human cell receptor present in lungs, intestine, kidney, and heart (Clerkin et al. 2020). This cell receptor serves as the entry point for some coronaviruses present in a diverse group of animals (Zhou et al. 2020) and regulates cross-species transmission (Wan et al. 2020). SARS-CoV-2 enters the body primarily through nose, eyes and mouth. From the time of initial exposure, it takes two weeks (14 days) for a person to develop symptoms called as incubation period, but, in some cases, it may be as long as 24 days (Abduljalil and Abduljalil 2020). First it infects upper respiratory tract causing dry cough and fever (Jiang et al. 2020) progressing to lower respiratory tract causing bronchitis and pneumonia (Huang et al. 2020) and gastrointestinal tract causing nausea and diarrhoea (Han et al. 2020). Pneumonia causes lung damage preventing oxygen movement to other organs. In such cases ventilators are required for oxygen supply to avoid death due to multiple organ failures (Guo et al. 2020). At present many countries are in crisis due to increased number of cases and limited ventilators.

Transmission of COVID-19 may occur from both symptomatic and asymptomatic patients. It is believed that asymptomatic patients carry a similar amount of virus as the symptomatic (Zou et al. 2020); therefore, it is possible to spread the virus even before symptoms emerge, termed as silent transmission. The possibility of asymptomatic 
individual spreading the virus cannot be overruled, and such individual needed to be isolated/quarantined at specialized facilities (Cai et al. 2020). Some people having travel history to infected countries/areas voluntarily quarantined themselves in their homes after informing officials. It is believed that one infected person will on average spread the virus to 2-4 individuals in normal condition (without lockdown) (CDPH 2020). Patients with COVID-19 are diagnosed by rRT-PCR, blood test, antibody test, CT scans (Bi et al. 2020).

Understanding the transmission of the infection and evaluating the effectiveness of control measure is crucial for assessing outbreak in new areas and in future (Kucharski et al. 2020). The novelty of the paper is that it discusses in detail the transmission, health impacts and mitigation strategies in detail at one place in order to help in better understanding of the problems and solutions related to COVID-19. The paper further analyses the impact of lockdown and social distancing measures on the spread of this contagious virus using Bayesian probabilistic modelling which is unique in its own way. Limited literature is available on using such type of modelling for strategic applications related to COVID-19. CPA analysed through this model helps in understanding the role of outbreak, its spread and outcome of mitigative strategies of selected country.

\section{Transmission of COVID-19}

COVID-19 had shown four phases of transmission throughout the world. Phase-I had shown controlled transmission with few cases having travel history to infected countries. Such cases were immediately isolated and treated in the designated hospitals. But at this moment there was no knowledge about the spread of virus through asymptomatic patients; therefore, disease progressed into next phase. Phase-II is the local transmission where virus spreads in local surroundings through symptomatic or asymptomatic patients having travel history. Phase-III is the community transmission where individuals having no connection with the asymptomatic and symptomatic patients start showing symptoms. At this phase other modes of transmission are also responsible for spread of disease and situation becomes uncontrollable. In the Phase-IV disease crossed borders resulting into interlintrastate transmission where number of cases and deaths had shown sudden increase resulting into epidemic. COVID-19 finally reached Phase-V where initial outbreak in China spread rapidly, affecting other countries in Europe, America, Africa, Asia and Middle East resulting into pandemic.

Initial transmission took place when infected individual travelled outside from Wuhan later declared as epicentre of COVID-19 outbreak (Ji et al. 2020). In December 2019, first patient (termed as index patient or patient zero) was reported with pneumonia in Wuhan, China, who believed to have visited seafood market. Later in last week of December, similar cases emerged and Wuhan Municipal Health Commission announced pneumonia outbreak of unknown cause. Meantime, Chinese Lunar New Year started in January where people travelled out of the city, and in some cases, overseas resident travelled to China. First few cases outside of China were reported in Bangkok, Thailand, Korea, Japan. Population of Wuhan was placed under lockdown, means no interstate and intrastate movement. By the end of January 2020, Singapore, Vietnam, USA, Nepal, Australia, Malaysia, Canada, Cambodia, Germany, Sri Lanka, United Arab Emirate (UAE), Finland, Philippines, UK, Russia, Sweden, Spain and India confirmed their first COVID-19 cases. WHO declared COVID-19 as disease of emergency that needed international attention. 
COVID-19 cases were reported with individuals having no travel history, suggesting that local transmission occurred in these countries.

In March 2020, more than 100 countries reported cases of COVID-19 and were declared pandemic by WHO. Airports were put on screening to detect symptomatic people returning from infected countries. In the second half of March 2020, China had shown decrease in new cases by adopting various mitigation measures, whereas Italy and Iran emerged as new hot spots. Europe became epicentre of the pandemic with more cases and deaths than rest of the world. By the end of March 2020, Italy surpassed China with maximum number of deaths. On the other hand, USA had experienced maximum number of confirmed cases in the world. Italy announced the need to extend the lockdown from March to April. By now all European countries were affected and reason for transmission was open border system. In March, USA had overtaken China and Italy with the highest number of confirmed cases. April experienced rising number of cases in all the African and Asian countries. USA became the country with the highest official death toll for COVID-19. By the end of April Russia emerged to become new hot spot with $2 \%$ of population infected and Africa decided to ease restrictions in some areas. In May 2020, Africa reported 54\% cases and $35 \%$ deaths with eight regions showing community transmission. On 11 May 2020, the first new cluster of cases in Wuhan was reported since the government lifted the lockdown. All the above information of COVID outbreak is retrieved from Devex.com.

Rise in number of cases in different weeks is presented in Table 1 where it can be observed that India, France and Japan had experienced increase in fifth week, that in USA and Spain in the fourth week, Italy in the third week except for Iran and China in second week. CPA is performed in Table 1 in order to understand the most impacting week for the countries in terms of either increase or stagnation in number of COVID-19 cases.

Many ongoing studies are trying to find out nature and path of transmission of SARS-CoV-2. As COVID-19 is progressing, transmission modes of SARS-CoV-2 are also showing variations (as shown in Fig. 1). COVID-19 is presumed to spread via droplets or aerosol spurted during coughing or sneezing, and airborne transmission happens when the residue from evaporated, infected droplets gets suspended in the air and

Table 1 Weekly cumulative statistics of COVID-19 of selected countries

\begin{tabular}{lrrrrrrrr}
\hline Week & India & \multicolumn{1}{l}{ USA } & France & Italy & Japan & Iran & Spain & China \\
\hline 1 & 3 & 11 & 6 & 3 & 4 & 95 & 2 & 278 \\
2 & 3 & 13 & 6 & 3 & 20 & 2336 & 2 & 2761 \\
3 & 3 & 15 & 11 & 400 & 26 & 8042 & 2 & 17,238 \\
4 & 3 & 12 & 3089 & 59 & 16,169 & 45 & 40,235 \\
5 & 34 & 108 & 38 & 12,462 & 144 & 21,638 & 589 & 70,635 \\
6 & 84 & 696 & 420 & 35,713 & 455 & 32,332 & 7753 & 77,262 \\
7 & 315 & 3536 & 2860 & 74,386 & 1054 & 50,468 & 28,572 & 80,174 \\
8 & 918 & 32,341 & 10,995 & 92,472 & 1693 & 58,226 & 83,749 & 81,439 \\
9 & 3072 & 140,223 & 29,155 & 124,632 & 3271 & 62,589 & 138,587 & 81,669 \\
10 & 7529 & 333,593 & 59,105 & 152,271 & 6748 & 73,303 & 171,981 & 82,052 \\
11 & 14,792 & 553,493 & 86,334 & 175,925 & 10,361 & 82,211 & 202,693 & 82,735 \\
12 & 24,942 & 750,718 & 108,847 & 195,351 & 13,182 & 89,328 & 228,610 & 82,827 \\
13 & 37,776 & $1,126,250$ & 120,804 & 209,328 & 14,839 & 95,646 & 248,028 & 82,877 \\
14 & 59,662 & $1,300,243$ & 129,581 & 218,268 & 15,747 & 104,691 & 264,670 & 82,901 \\
\hline
\end{tabular}




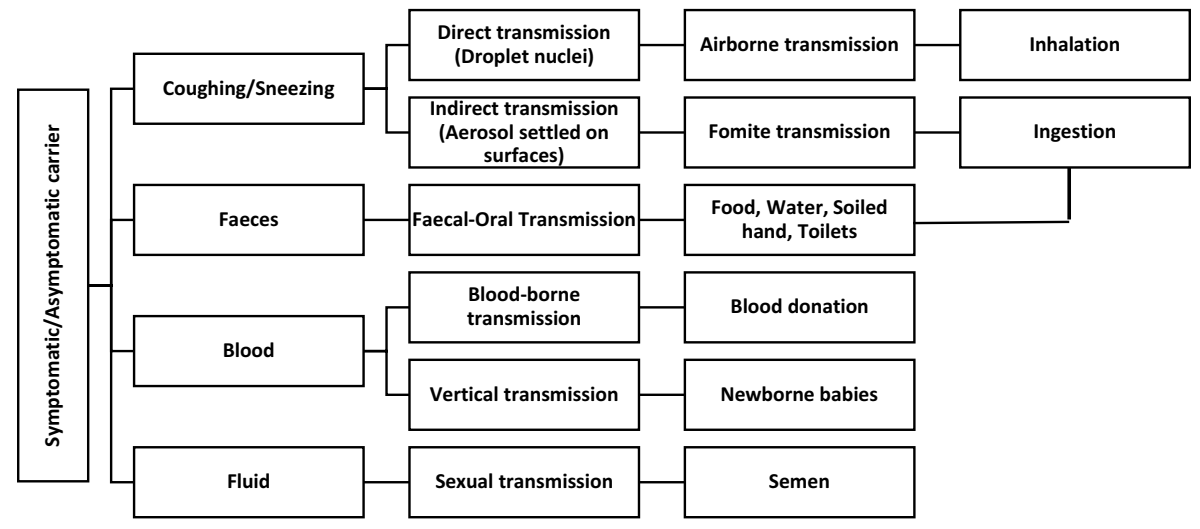

Fig. 1 Flow diagram explaining different modes of transmission of SARS-CoV-2

infects those who breathe in it (Gautam and Trivedi 2020; Santarpia et al. 2020). Droplet transmission is nosocomial droplet nuclei carrying pathogens from the infectious individual to recipient or falls on the surface (Yang et al. 2016). An individual can also become infected by touching a contaminated surface resulting into fomite transmission (Liu et al. 2020a, b). Coronaviruses have been observed to remain viable for few hours on aerosols, copper, printing papers, tissue papers and for few days on cardboard, stainless steel, plastics, treated wood, glass, banknotes (Chin et al. 2020 Doremalen et al. 2020). Recently, a study in Italy reports adherence of SARS-CoV-2 on particulate matter in conditions of stable atmosphere and high concentration (Setti et al. 2020). This can result into carrier transmission of the virus for a longer distance. In such case, it is important to perform quantitative risk assessment to find out possible health problem caused by inhalation of dust carrying SARS-CoV-2.

SARS-CoV-2 was also reported in the stool samples of patients, suggesting that viral shedding in stool could be a potential route of faecal-oral transmission (Ong et al. 2020). Therefore, there are chances of virus transfer from toilet product to food and water through soiled hands (Zhang et al. 2020a, b, c). Virus has also been reported in blood samples, but chance of blood-borne transmission is not clear. Although during blood donation, proper care should be taken to identify asymptomatic patient (Chang et al. 2020). Scientists are collecting plasma and serum of infected patients for further studies on COVID-19. During pregnancy immune system is low resulting into manifestation of COVID-19 symptoms (Dong et al. 2020). With regard to vertical transmission, i.e. transmission from mother to baby, there is no case reported where foetus is infected from mother. However, infants could become infected during delivery or while breastfeeding from infected mother. Hospitals are also at risk for transmission of virus among health workers through medical equipments, apparels and procedures. The highest concentration of SARS-CoV-2 was observed inside the patient toilet room (Liu et al. 2020a, b) when compared other areas where patient lives. There are other multiple sources from where transmission of SARS-CoV-2 can take place such as home, transport, restaurant, theatre, shopping mall and supermarket. Transmission in the mall was traced among workers and customers via elevator buttons or restroom taps, elevators etc. (Cai et al. 2020).

Researchers around the world were speculating seasonal transmission, where COVID19 will exist in winters, and as soon as temperature will rise, there are chances of less 
transmission. Therefore, spread of cases is dependent on temperature and humidity (Bherwani et al. 2020a). It was estimated that $1{ }^{\circ} \mathrm{C}$ rise in temperature reduces transmission by $13 \%$ (Carleton and Meng 2020). Doubling time correlates positively with temperature and inversely with humidity (Oliveiros et al. 2020). But increase of temperature would alone not necessarily lead to decline in cases, but it should also be coupled with other mitigation measures. It was believed that developing countries with lack of medical facilities will face more mortality than developed countries. But in reality, given the present scenario developed countries had more cases and mortality as opposed to developing countries. It is believed that higher mortality in developed countries is due to the presence of elder populations, whereas developing countries have a younger population (Walker et al. 2020). It was reported that children are least affected, whereas the elderly are experiencing highest rate of deaths (Guo et al. 2020). Children tend to make more social contacts than adults and therefore contribute more to transmission than adults (Davies et al. 2020). It was also evident that more symptoms were visible with age above 60 years and there were no cases in children below 15 years of age ( $\mathrm{Li}$ et al. 2020a, b; Zhang et al. 2020a, b, c). Average recovery time for COVID-19 is estimated to be 22 days with 19 days for young people and 22 days for older groups ( $\mathrm{Bi}$ et al. 2020). It was reported that mortality rate in Italy $(5.4 \%)$ was higher than China (2.3\%) due to the presence of elderly population (Abduljalil and Abduljalil 2020). Cases were more in males and between the ages of 20-69 years (Bi et al. 2020). Recent study in China surprisingly reported SARS-CoV-2 in the semen of male patients raising new debate on sexual transmission of the disease (Li et al. 2020a, b).

With every passing time new development related to COVID-19 is stated with respect to transmission mode and transmission rate. Other possibilities of transmission from human to pet transmission, waterborne transmission, transmission through air etc. (Gautam and Hens 2020; Gautam 2020a) are speculated but remain uncertain. It is an initial phase of this pandemic and is believed that COVID-19 will take longer time to get completely eradicated. However, control measures can slow down the speed as well as mortality rate.

\section{Mitigation methods adopted to control COVID-19}

Immediate and strategic response to mitigation plays an important role in influencing the trajectory of this pandemics across the world. In case of Wuhan, China, there was decline in transmission when control measures were introduced (Kucharski et al. 2020). It was estimated that the absence of mitigation measure would lead to 7 billion infections and 4 billion deaths (Walker et al. 2020). Various measures are undertaken to prevent infection such as maintaining hygiene, using facemasks, isolation/quarantine, social distancing, in extreme cases lockdown in hot spot areas.

Proper hygiene practices were encouraged such as covering the nose/mouth with tissue or elbow while coughing/sneezing and avoid touching surfaces (Bruin et al. 2020). The use of hand sanitizer or washing hand with soap for 20 secs after sneezing or touching contaminated surfaces was essential. Surfaces were decontaminated with many solutions such as ethanol, isopropyl alcohol, sodium hypochlorite bleach, hydrogen peroxide. Face masks became an essential component but was recommended only when having symptoms or treating patients. Its importance was apparent from the fact that one patient without facemask transmitted virus to five other people while travelling in a vehicle in China (Liu and Zhang 2020; Liu et al. 2020a, b). In developing countries, due to lack of sufficient medical mask, people started use of local cloth mask. Cotton mask could be a potential substitute 
for medical mask as there is no significant difference for reducing droplet transmission. Cotton mask is washable and re-usable also (Ho et al. 2020).

Health, transportation, safety, security and infrastructure workers were at highest risk of getting infected and therefore were provided first priority for personal protective equipment (PPE). Source control by masking of patients and visitors by using N95 or higher-level respirators, using telemedicine, designating separate locations/rooms for care also helped in reducing risk of SARS-CoV-2 transmission in health workers (Heinzerling et al. 2020). The virus may be resuspended from the contaminated PPE surface to the air; therefore, sanitization before they are taken off was carried out to reduce the infection risk for health and other workers (Gautam 2020b; Liu et al. 2020a, b). At present, there is no definite vaccine present to treat COVID-19, but many medicines such as remdesivir, chloroquine, lopinavir and ritonavir were successfully used as an alternative (Gabriella et al. 2020; Guo et al. 2020).

Social/physical distancing was encouraged by avoiding groups and keeping safe distance of 1-2 m (Bruin et al. 2020). Social distancing when coupled with isolation/restrictions likely to control the disease within 13-14 weeks and reduced peak incidence by 40-60\% was estimated (Chang et al. 2020; Zhang et al. 2020a, b, c). Isolation practices can be effective for preventing secondary transmission of viruses (Basile et al. 2020). About $80 \%$ of individuals needed to be traced and isolated to attain $90 \%$ control over outbreak (Hellewell et al. 2020). In hot spot areas with highest number of cases lockdown was imposed in many countries. It included complete closure of public transport, public places, educational institution, hotels, offices, factories, etc. Lockdown resulted into decline of transmission of disease to half (Kucharski et al. 2020). China initiated lockdown to control the disease followed by Italy, France, Spain, Philippines, India and other countries.

Technology intervention such as the use of digital technologies for screening infected individuals was vital in controlling transmission and slowing pace of the disease in Taiwan, Singapore, Hong Kong and South Korea. Countries around the world launched websites/ apps to combat misinformation regarding disease, medication and encourage awareness. Some of the examples are Self Diagnosis App (South Korea), EuroMOMO (Europe), Aarogya Setu (India), Mask app (Iran), Trace Covid (UAE), Crush Covid app (USA), CoronaWarn app (Germany), StopCovid app (France), Covid-Safe app (Australia), Tracetogether app (Singapore), Immuni app (Italy) COVID-19 GIS Dashboard by John Hopkins CSSE (USA), Worldometer coronavirus tracker, WHO COVID-19 Dashboard, COVID-19 India tracker, etc. This tracker app shows total number of cases in surrounding area and alerts about hot spot/containment zone. Also, e-pass is provided in case of the absence of corona symptoms.

\section{Bayesian Probability Modelling for COVID-19 Transmission}

It is recognized that the SARS-CoV-2 is highly contagious and till the medications are being explored, and social/physical distancing along with hygiene is the only saviours (Bherwani et al. 2020a). CPA is performed in Table 1 in order to understand the most impacting week for the countries in terms of either increase or stagnation in number of COVID-19 cases. The countries were chosen based on better availability of data. Pythonbased PyMC3 is used for CPA.

The above probabilistic programming of Python is used to fit Bayesian models using varied numerical methods (Salvatier et al. 2016). Here this model is used as per the concept 


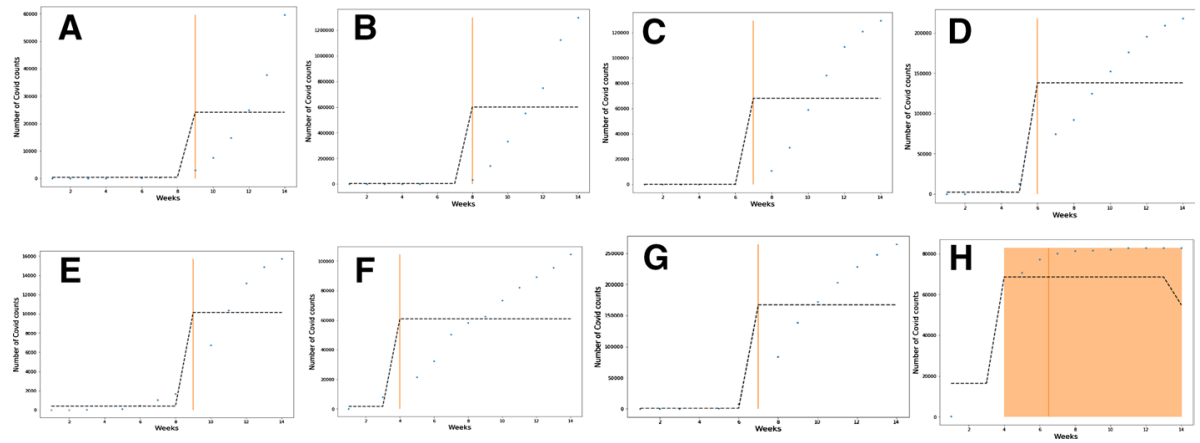

Fig. 2 CPA results for each selected country

Table 2 Significance of change point with respect to lockdown

\begin{tabular}{llllll}
\hline Country & $\begin{array}{l}\text { Date of first } \\
\text { case reporting } \\
\left(\mathrm{D}_{\mathrm{fr}}\right)\end{array}$ & Lockdown date $\left(\mathrm{D}_{1}\right)$ & $\begin{array}{l}\text { Case weeks } \\
\text { before lockdown } \\
\left\{\mathrm{CW}=\left(\mathrm{D}_{1}-\mathrm{D}_{\mathrm{fr}}\right) / 7\right\}\end{array}$ & CP week $\left(\mathrm{CP}_{\mathrm{w}}\right)$ & $\begin{array}{l}\text { Delta } \\
\left(\mathrm{D}=\mathrm{CP}_{\mathrm{w}^{-}}\right. \\
\mathrm{CW})\end{array}$ \\
\hline India & 30 Jan & $25 \mathrm{Mar}$ & 7.9 & 9 & 1.1 \\
USA & 13 Jan & $19 \mathrm{Mar}$ & 9.4 & 8 & -1.4 \\
France & 24 Jan & $17 \mathrm{Mar}$ & 7.6 & 7 & -0.6 \\
Italy & 31 Jan & 09 Mar & 5.4 & 6 & 0.6 \\
Japan & 04 Jan & 27 Feb & 7.7 & 9 & 1.3 \\
Iran & 19 Feb & 28 Mar & 5.4 & 4 & -1.4 \\
Spain & 31 Jan & 14 Mar & 6.1 & 7 & 0.9 \\
China & 31 Dec & 25 Jan & 3.6 & 6.5 & 2.9 \\
\hline
\end{tabular}

that more than frequency of any parameter, the reasonability and expectation of an event are more important. In such circumstances Bayesian probability is usually used. Proportional logic is used to derive the reasoning of interaction. The assessment could have been carried using other methods of probability; however, the above method suits the best under the given circumstances. Similar approaches have been used in past as well (Aminikhanghahi and Cook 2017; Bherwani et al. 2020c). The model is built for series of data (Table 1), and CPA is determined for each country, viz. India (A), USA(B), France(C), Italy(D), $\operatorname{Japan}(\mathrm{E})$, Iran(F), Spain $(\mathrm{G})$, and China(H). The results of CPA are shown in Fig. 2A-H and summarized in Table 2. The raw images of Fig. 1 are given in Appendix. The orange line indicates the point where drastic change has occurred in the number of COVID-19 cases in each of the respective countries, referred to as change point (CP). It can be seen that each country had shown a different response to the pandemic except China is showing a band rather than a point of change, as the cases suddenly increased and stabilized in the country. 
CPA is further analysed in reference to the first cases which are observed in respective countries and the day on which lockdown is initiated as shown in Table 2. This is important in order to understand if the lockdown is initiated before or after change point. The difference gives a significant information. Table 2 indicates the list of countries which were able to act fast and start physical distancing measures before the catastrophe (point of change) occurred in terms of exponential rise of COVID-19 cases. Countries including India, Italy, Japan, Spain and China acted relatively fast. While Italy and Spain have suffered with many cases and fatalities, India, Japan and China have been able to contain the spread and flatten the curve given their steady rise in cases. USA, which acted very late, has borne the brunt of the virus which is visible in their exponential rise and sheer magnitude of number of cases in such a short time. While the CPA indicates the importance of social distancing, it is worthwhile to explore its linkage with COVID-19 by adding one more parameter of population, i.e. normalized population and population density. Table 3 gives a comparative analysis of the same.

Table 3 is arranged in decreasing order of cases per unit population density (CPD), which is an indicator of penetration of COVID-19 into the country. It can be clearly seen that the countries which acted late have more cases per unit population density. USA and Iran with the slowest response have the maximum CPD. Iran is standing below USA, probably due to lower absolute population. Furthermore, Spain had an earlier response than Italy and was able to control CPD better despite having higher population and population density. India and Japan had an ascendency in terms of delta (d), indicating the early action, and are the lowest in terms of CPD. India is best among the lot probably because of executing one of the most stringent lockdowns ever. China is an exception due to facts stated above. The results are represented in Fig. 3 with $\log _{10}$ values of CPD considered for normalization of scale. It indicates that with increase in the values of delta, there is steady drop in $\log _{10}$ CPD values. Further analysis is carried out for countries having positive delta (except China) in terms of their linear correlation with population parameters. The results are shown in the form of lower triangular matrix in Table 4.

From Table 4, it can be inferred that $\mathrm{D}$ is in strong inverse correlation with number of cases, CPP and CPD with factors of $-0.86,-0.97$ and -0.97 , respectively. This indicates that more the value of delta, lesser are the CPP, CPD and $C$ values which establishes the

Table 3 CPA results in relation to cases and population

\begin{tabular}{lllrllc}
\hline Country & Delta (D) & Cases (C) & Population (P) & $\begin{array}{l}\text { Population } \\
\text { density (PD) }\end{array}$ & $\begin{array}{l}\text { Cases/popu- } \\
\text { lation (CPP) }\end{array}$ & Cases/density (CPD) \\
\hline USA & -1.43 & $1,300,243$ & $33,10,02,651$ & 36 & 0.00393 & $36,117.86$ \\
Iran & -1.43 & 104,691 & $8,39,92,949$ & 52 & 0.00125 & 2013.29 \\
France & -0.57 & 129,581 & $6,52,73,511$ & 119 & 0.00199 & 1088.92 \\
Italy & 0.57 & 218,268 & $6,04,61,826$ & 206 & 0.00361 & 1059.55 \\
Spain & 0.86 & 264,670 & $12,64,76,461$ & 347 & 0.00209 & 762.74 \\
China & 2.93 & 82,901 & $1,43,93,23,776$ & 153 & 0.00006 & 541.84 \\
Japan & 1.29 & 15,747 & $4,67,54,778$ & 94 & 0.00034 & 167.52 \\
India & 1.14 & 59,662 & $1,38,00,04,385$ & 464 & 0.00004 & 128.58 \\
\hline
\end{tabular}




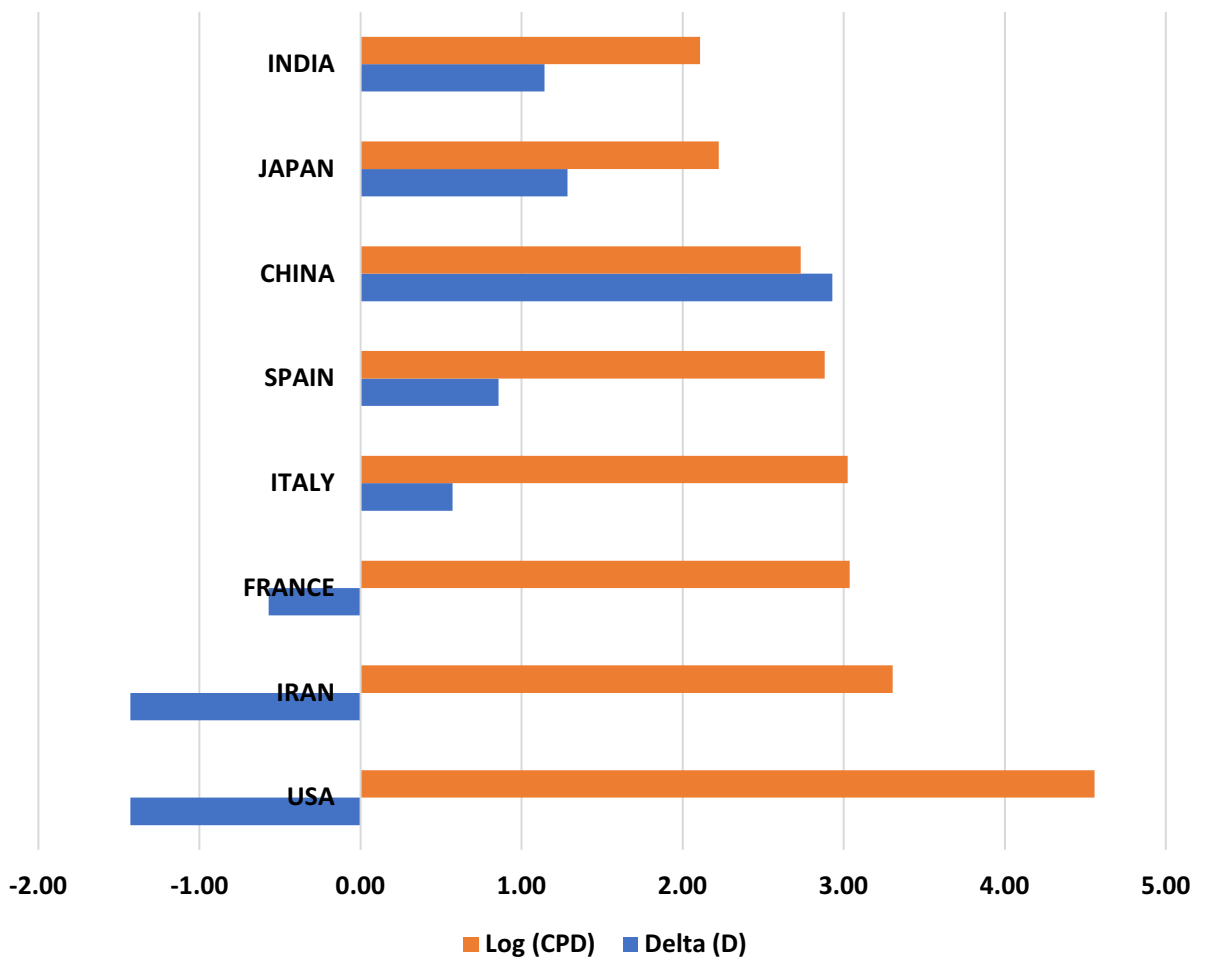

Fig. 3 Importance of early action in control of COVID-19 spread

Table 4 Correlation matrix for delta and population parameters

\begin{tabular}{lrrrrrr}
\hline & \multicolumn{1}{l}{$D$} & \multicolumn{1}{l}{$C$} & \multicolumn{1}{l}{$P$} & \multicolumn{1}{c}{$P D$} & $C P P$ & $C P D$ \\
\hline $\mathrm{D}$ & 1.00 & & & & & \\
$\mathrm{C}$ & -0.86 & 1.00 & & & & \\
$\mathrm{P}$ & 0.36 & -0.41 & 1.00 & & & \\
$\mathrm{PD}$ & -0.03 & 0.19 & 0.80 & 1.00 & & \\
$\mathrm{CPP}$ & -0.97 & 0.83 & -0.58 & -0.21 & 1.00 & \\
$\mathrm{CPD}$ & -0.97 & 0.89 & -0.57 & -0.14 & 0.99 & 1.00 \\
\hline
\end{tabular}

hypothesis that lockdown and physical distancing are playing a major role in reducing the intensity and magnitude of cases of COVID-19. Also, population density is an important factor when it comes to the spread of the virus which reconfirms the causation that the virus is highly contagious in nature and physical distancing is one of the most efficient ways to control its spread. While there is sufficient evidence that the extremely contagious nature of this virus and population density are playing an important role in spread of 
COVID-19, it is important to note that as the world moves through this pandemic, the models will have to be adapted to improve the predictions and the same is true for the above modelling exercise as well.

\section{Discussion and Conclusion}

COVID-19 has proven to be once in lifetime pandemic that a generation will ever experience. It is a silent war that a human is fighting with an organism of nanosize. Developed countries claiming their efficiency in health and other facilities have given up to the atrocities created by this virus. The virus which is named as SARS-CoV-2 has its presence in every country and continent across the world. It is transmitted from Horseshoe bat (natural host) through Malayan pangolin (intermediate host) finally to the humans. First detected in China and then spread rapidly in other countries initially from people having travel history to infected countries. Airborne, droplet and fomite transmission are held responsible for local transmission. Population were encouraged to use hand sanitizers, soap, facemask/face covering, etc., to prevent from COVID-19. It is believed that increase in temperature in coming months will also help to slow the pace of COVID-19 and death rates will decrease. It is reported that COVID-19 mostly effects and elderly population (Fig. 4).

The paper explores the efficacy of the lockdowns and social distancing polices followed by eight countries suffering from COVID-19 pandemic. While lockdown has a strong effect on the economy and many people will lose their jobs, creating financial insecurity, lockdown seems to be an efficient way of controlling the spread (Bherwani et al.

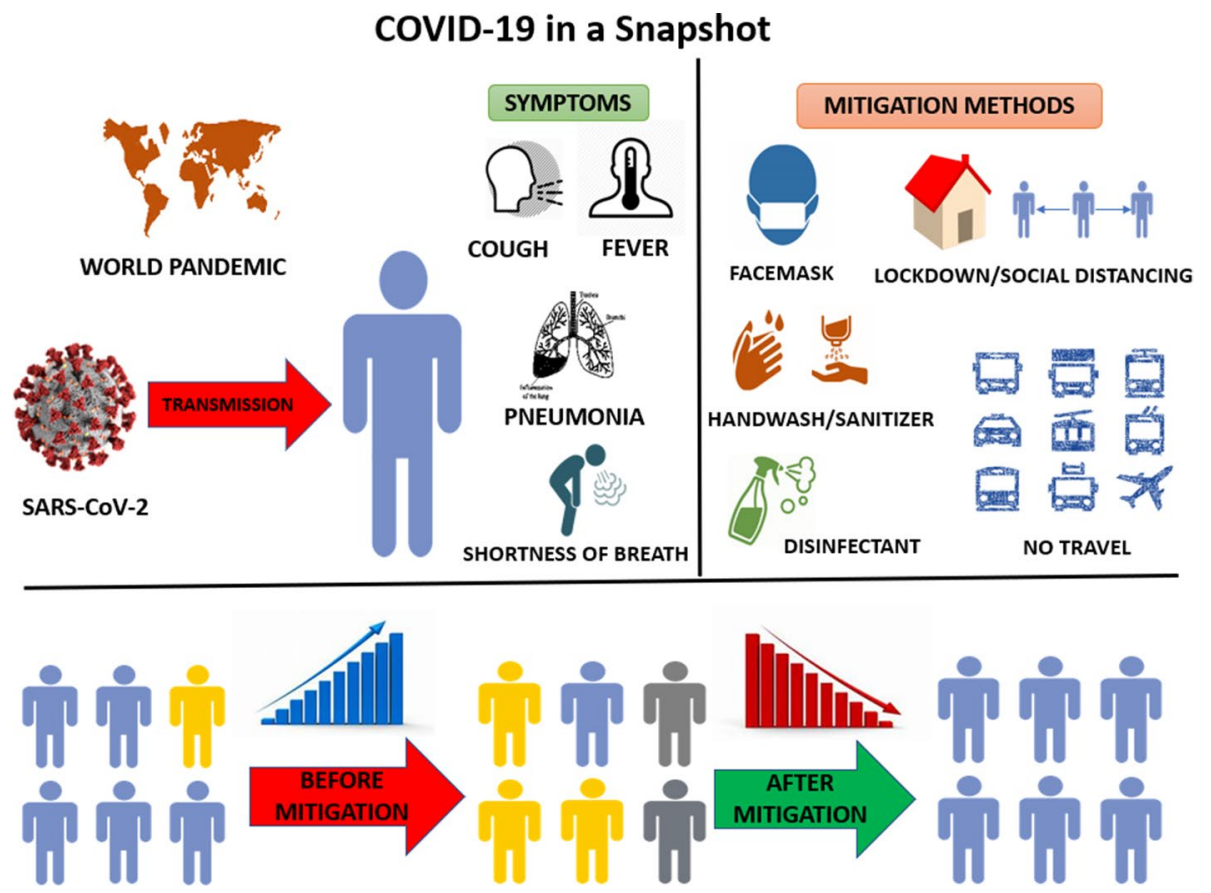

Fig. 4 Transmission of COVID-19 symptom, mitigation measures adopted and effect on population 
2020b). CPA showed that social distancing and lockdown have helped many countries to bring down their number. The countries which were able to act before the curve became exponential and implemented their social/physical distancing measures have been able to contain their numbers. A strong inverse correlation between the time of action, represented by delta, and the number of cases (Pearson's $r=-0.86$ ), cases per unit population and population density (Pearson's $r=-0.97$ ), are representative of depth of penetration of the disease. It is evidently seen the countries like India and Japan are among those who introduced lockdowns and distancing measures way early during the spread have much less cases, rate of increase of cases, while on the other hand, countries like USA, Italy, Spain and France have been suffering due to the late action on the above mitigation measures. The outcome of the research not only helps the countries which are still struggling with the virus, especially developing countries, but also it is helpful for the expected second wave of the virus. The analysis can be used to develop strategies related to mitigation and control of the spread of virus as it indicates the population density is one of the major factors driving the spread. Future research on similar lines can be carried out to understand the effect of life style and pre-existing conditions similar to population density using the above given novel approach.

Acknowledgement Authors acknowledge Council of Scientific and Industrial Research (CSIR), India, and its constituent laboratory National Environmental Engineering Research Institute (NEERI) for providing the support for the research. The manuscript is checked for plagiarism using licensed iThenticate software wide KRC No.: CSIR-NEERI/KRC/2020/MAY/MZC-CSUM-DZC-DRC-DIR/1

\title{
Compliance with ethical standards
}

Conflicts of interest The authors declare that there are no conflicts of interest regarding the publication of this manuscript.

\section{Appendix: Raw Images of Change Point Analysis}

\author{
See Fig. 5.
}



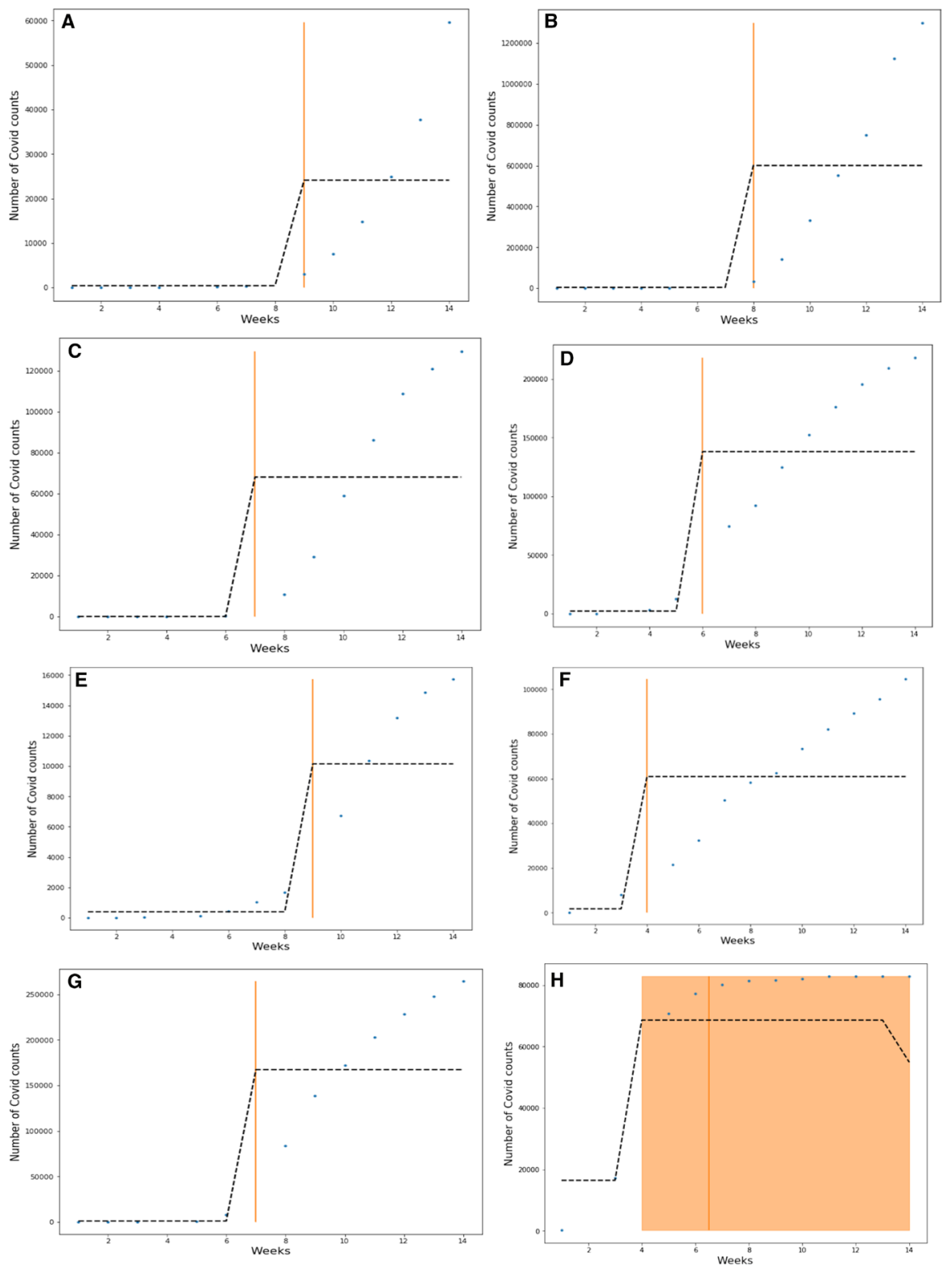

Fig. 5 Results for each selected country a India, b USA, c France, d Italy, e Japan, f Iran, g Spain, (H) China

\section{Additional Data}

1. COVID-19 daily cases of India data available online: https://www.indiatoday.in/india/ story/coronavirus-cases-in-india-covid19-states-cities-affected-1653852-2020-03-09 Accessed on (11 May 2020) 
2. COVID-19 daily cases of USA data available online: https://coronavirus-responsealaska-dhss.hub.arcgis.c Accessed on (11 May 2020)

3. COVID-19 daily cases of France data available online: https://www.worldometers.info/ coronavirus/country/france/ Accessed on (11 May 2020)

4. COVID-19 daily cases of Italy data available online: https://www.worldometers.info/ coronavirus/country/italy/ Accessed on (11 May 2020)

5. COVID-19 daily cases of Japan data available online: https://toyokeizai.net/sp/visua 1/tko/covid19/en.html Accessed on (11 May 2020)

6. COVID-19 daily cases of Iran data available online: https://www.worldometers.info/ coronavirus/country/iran/ Accessed on (11 May 2020)

7. COVID-19 daily cases of Spain data available online: https://www.worldometers.info/ coronavirus/country/spain/ Accessed on (11 May 2020)

8. COVID-19 daily cases of China data available online: https://www.worldometers.info/ coronavirus/country/china/ Accessed on (11 May 2020)

9. First spotted cases timeline data: https://www.bbc.com/news/world-52103747 Accessed on (11 May 2020)

10. COVID-19 pandemic alarm of lockdown: https://www.bbc.com/news/world-52103 747 Accessed on (11 May 2020)

11. Population data: https://www.worldometers.info/world-population/

12. Population density: https://worldpopulationreview.com/countries/countries-by-densi tyl

\section{References}

Abduljalil, J. M., \& Abduljalil, B. M. (2020). Epidemiology, genome, and clinical features of the pandemic SARS-CoV-2: A recent view. New Microbes and New Infections, 35, 100672. https://doi. org/10.1016/j.nmni.2020.100672.

Aminikhanghahi, S., \& Cook, D. J. (2017). A survey of methods for time series change point detection. Knowledge and Information Systems, 51(2), 339-367. https://doi.org/10.1007/s10115-016-0987-z.

Andersen, K. G., Rambaut, A., Lipkin, W. I., Holmes, E. C., \& Garry, R. F. (2020). The proximal origin of SARS-CoV-2. Nature medicine, 26(4), 450-452. https://doi.org/10.1038/s41591-020-0820-9.

Basile, C., Combe, C., Pizzarelli, F., et al. (2020). Recommendations for the prevention, mitigation and containment of the emerging SARS-CoV-2 (COVID-19) pandemic in haemodialysis centres. Nephrology, Dialysis, Transplantation: Official Publication of the European Dialysis and Transplant Association European Renal Association, 35(5), 737-741. https://doi.org/10.1093/ndt/gfaa069.

Benvenuto, D., Giovanetti, M., Salemi, M., et al. (2020). The global spread of 2019-nCoV: a molecular evolutionary analysis. Pathogens and Global Health, 114(2), 64-67. https://doi.org/10.1080/20477 724.2020 .1725339 .

Bherwani, H., Gupta, A., Anjum, S., Anshu, \& A., Kumar, R. Exploring Dependence of COVID-19 on Environmental Factors and Spread Prediction in India, Advance online publication. (2020a) (Version 1) available at Research Square [10.21203/rs.3.rs-256]

Bherwani, H., Nair, M., Musugu, K., et al. (2020). Valuation of air pollution externalities: comparative assessment of economic damage and emission reduction under COVID-19 lockdown. Air Quality, Atmosphere and Health. https://doi.org/10.1007/s11869-020-00845-3.

Bherwani, H., Anjum, S., Kumar, S., Gautam, S., Gupta, A., Kumbhare, H., Anshul A., and Kumar R. Understanding COVID-19 transmission through Bayesian probabilistic modelling and GIS-based Voronoi approach: a policy perspective (2020c). https://doi.org/10.1007/s10668-020-00849-0

Bi, Q., Wu, Y., Mei, S. et al. (2020). Epidemiology and Transmission of COVID-19 in Shenzhen China: Analysis of 391 cases and 1,286 of their close contacts. (Advance online publication). https://doi. org/10.1101/2020.03.03.20028423 
Bruin, Y., Lequarre, A. S., McCourt, J. et al. (2020). Initial impacts of global risk mitigation measures taken during the combatting of the COVID-19 pandemic. Safety science, 104773. (Advance online publication). https://doi.org/10.1016/j.ssci.2020.104773

Cai, J., Sun, W., Huang, J., Gamber, M., Wu, J., \& He, G. (2020). Indirect Virus Transmission in Cluster of COVID-19 Cases, Wenzhou, China, 2020. Emerging Infectious Diseases 26(6). https://doi. org/10.3201/eid2606.200412

California Department of Public Health (2020) COVID-19 Health care system mitigation playbook, https:// www.cdph.ca.gov/Programs/CHCQ/LCP/Pages/AFL-20-23.aspx

Carleton, T., \& Meng, K. C. (2020). Causal empirical estimates suggest COVID-19 transmission rates are highly seasonal. Advance online publication. https://doi.org/10.1101/2020.03.26.20044420.

Chang, L., Yan, Y., \& Wang, L. (2020). Coronavirus Disease 2019: Coronaviruses and Blood Safety. Transfusion medicine reviews. (Advance online publication).. https://doi.org/10.1016/j.tmrv.2020.02.003.

Clerkin, K. J., Fried, J. A., Raikhelkar, J., et al. (2020). COVID-19 and Cardiovascular Disease. Circulation, 141, 1648-1655. https://doi.org/10.1161/CIRCULATIONAHA.120.046941.

Davies, N. G., Klepac, P., Liu, Y., et al. (2020). Age-dependent effects in the transmission and control of COVID-19 epidemics. Advance online publication. https://doi.org/10.1101/2020.03.24.20043018.

Dong, L., Tian, J., He, S., Zhu, C., Wang, J., Liu, C., et al. (2020). Possible Vertical Transmission of SARSCoV-2 From an Infected Mother to Her Newborn. JAMA, 323(18), 1846-1848. https://doi.org/10.1001/ jama.2020.4621.

Doremalen, N., Bushmaker, T., Morris, D. H., et al. (2020). Aerosol and Surface Stability of SARS-CoV-2 as Compared with SARS-CoV-1. The New England Journal of Medicine, 382(16), 1564-1567. https:// doi.org/10.1056/NEJMc2004973.

Gabriella, M., Cristina, S., Concetta, R., Francesco, R., \& Annalisa, C. (2020). SARS-Cov-2 infection: Response of human immune system and possible implications for the rapid test and treatment. International Immunopharmacology, 84, 106519. https://doi.org/10.1016/j.intimp.2020.106519.

Gautam, S. (2020a). COVID - 19: Air pollution remains low as people stay at home. Air Quality Atmosphere and Health. https://doi.org/10.1007/s11869-020-00842-6.

Gautam, S. (2020). The influence of COVID - 19 on air quality in India: A boon or inutile. Bulletin of Environmental Contamination and Toxicology, 104(6), 724-726.

Gautam, S., \& Hens, L. (2020). SARS-CoV-2 pandemic in India: What might we expect? Environmental Development and Sustainability, 22, 3867-3869.

Gautam, S., \& Trivedi, U. K. (2020). Global Implication of Bioaerosol in Pandemic. Environmental Development and Sustainability, 22, 3861-3865.

Guo, Y. R., Cao, Q. D., Hong, Z. S., et al. (2020). The origin, transmission and clinical therapies on coronavirus disease 2019 (COVID-19) outbreak - an update on the status. Military Medical Research, 7(1), 11. https://doi.org/10.1186/s40779-020-00240-0.

Han, C., Duan, C., Zhang, S., et al. (2020). Digestive symptoms in COVID-19 patients with mild disease severity: clinical presentation, stool viral RNA testing, and outcomes. The American Journal of Gastroenterology. https://doi.org/10.14309/ajg.0000000000000664.

Heinzerling, A., Stuckey, M. J., Scheuer, T. et al. (2020). Transmission of COVID-19 to Health Care Personnel During Exposures to a Hospitalized Patient - Solano County, California, February 2020. MMWR. Morbidity and mortality weekly report, 69(15), 472-476. https://doi.org/10.15585/ mmwr.mm6915e5

Hellewell, J., Abbott, S., Gimma, A., et al. (2020). Feasibility of controlling COVID-19 outbreaks by isolation of cases and contacts. The Lancet. Global Health, 8(4), e488-e496. https://doi.org/10.1016/ S2214-109X(20)30074-7.

Ho, K. F., Lin, L. Y., Weng, S. P., \& Chuang, K. J. (2020). Medical mask versus cotton mask for preventing respiratory droplet transmission in microenvironments. Science of Total Environment. https:// doi.org/10.1016/j.scitotenv.2020.139510.

Huang, C., Wang, Y., \& Li, X. (2020). Clinical features of patients infected with 2019 novel coronavirus in Wuhan, China. Lancet (London, England), 395(10223), 497-506. https://doi.org/10.1016/S0140 $-6736(20) 30183-5$

Ji, W., Wang, W., Zhao, X., Zai, J., \& Li, X. (2020). Cross-species transmission of the newly identified coronavirus 2019-nCoV. Journal of medical virology, 92(4), 433-440. https://doi.org/10.1002/jmv.25682.

Jiang, F., Deng, L., Zhang, L., Cai, Y., Cheung, C. W., \& Xia, Z. (2020). Review of the Clinical Characteristics of Coronavirus Disease 2019 (COVID-19). Journal of General Internal Medicine, 35(5), 1545-1549. https://doi.org/10.1007/s11606-020-05762-w.

Kucharski, A. J., Russell, T. W., Diamond, C., et al. (2020). Early dynamics of transmission and control of COVID-19: a mathematical modelling study. The Lancet: Infectious Diseases. https://doi. org/10.1016/S1473-3099(20)30144-4. 
Lam, T. T., Shum, M. H., Zhu, H., et al. (2020). Identifying SARS-CoV-2 related coronaviruses in Malayan pangolins. Nature. https://doi.org/10.1038/s41586-020-2169-0.

Lau, S., Luk, H., Wong, A., et al. (2020). Possible Bat Origin of Severe Acute Respiratory Syndrome Coronavirus 2. Emerging Infectious Diseases. https://doi.org/10.3201/eid2607.200092.

Li, D., Jin, M., Bao, P., Zhao, W., \& Zhang, S. (2020). Clinical characteristics and results of semen tests among men with coronavirus disease 2019. JAMA Network Open, 3(5), e208292. https://doi. org/10.1001/jamanetworkopen.2020.8292.

Li, Q., Guan, X., Wu, P., et al. (2020). Early transmission dynamics in Wuhan, China, of novel coronavirus-infected pneumonia. The New England Journal of Medicine, 382(13), 1199-1207. https://doi. org/10.1056/NEJMoa2001316.

Liu, X., \& Zhang, S. (2020). COVID-19: Face masks and human-to-human transmission. Influenza and Other Respiratory Viruses. https://doi.org/10.1111/irv.12740.

Liu, Y., Gayle, A. A., Wilder-Smith, A., \& Rocklöv, J. (2020). The reproductive number of COVID-19 is higher compared to SARS coronavirus. Journal of Travel Medicine, 27, 2. https://doi.org/10.1093/ $\mathrm{jtm} / \mathrm{taaa021.}$

Liu, Y., Ning, Z., Chen, Y., Guo, M., et al. (2020). Aerodynamic Characteristics and RNA Concentration of SARS-C. Advance online publication. https://doi.org/10.1101/2020.03.08.982637.

Lu, R., Zhao, X., Li, J., et al. (2020). Genomic characterisation and epidemiology of 2019 novel coronavirus: implications for virus origins and receptor binding. Lancet (London, England), 395(10224), 565-574. https://doi.org/10.1016/S0140-6736(20)30251-8.

Oliveiros, B., Caramelo, L., Ferreira, N.C., \& Caramelo, F. (2020). Role of temperature and humidity in the modulation of the doubling time of COVID-19 cases, medRxiv 2020.03.05.20031872. https:// doi.org/10.1101/2020.03.05.20031872

Ong, S., Tan, Y. K., Chia, P. Y., Lee, T. H., Ng, O. T., Wong, M., et al. (2020). Air, surface environmental, and personal protective equipment contamination by severe acute respiratory syndrome coronavirus 2 (SARS-CoV-2) from a symptomatic patient. JAMA, 323(16), 1610-1612. https://doi. org/10.1001/jama.2020.3227.

Paraskevis, D., Kostaki, E. G., Magiorkinis, G., Panayiotakopoulos, G., Sourvinos, G., \& Tsiodras, S. (2020). Full-genome evolutionary analysis of the novel corona virus (2019-nCoV) rejects the hypothesis of emergence as a result of a recent recombination event. Infect Genet Evol., 79, 104212. https://doi.org/10.1016/j.meegid.2020.104212.

Rajgor, D. D., Lee, M. H., Archuleta, S., Bagdasarian, N., \& Quek, S. C. (2020). The many estimates of the COVID-19 case fatality rate. The Lancet. Infectious Diseases, S1473-3099 (20) 30244-9. https ://doi.org/10.1016/S1473-3099(20)30244-9

Salvatier, J., Wiecki, T. V., \& Fonnesbeck, C. (2016). Probabilistic programming in Python using PyMC3. PeerJ Computer Science., 2, e55. https://doi.org/10.7717/peerj-cs.55.

Santarpia, J. L., Rivera, D. N., Herrera, V. (2020). Transmission potential of SARS-CoV-2 in viral shedding observed at the University of Nebraska Medical Center. Advance online publication. https://doi. org/10.1101/2020.03.23.20039446

Setti, L., Fabrizio, P., de gennaro Gianluigi, Baribieri, P. et al. (2020). SARS-Cov-2 RNA Found on Particulate Matter of Bergamo in Northern Italy: First Preliminary Evidence. (Advance online publication). https://doi.org/10.1101/2020.04.15.20065995

Smith, E. C., \& Denison, M. R. (2012). Implications of altered replication fidelity on the evolution and pathogenesis of coronaviruses. Current opinion in virology, 2(5), 519-524. https://doi.org/10.1016/j. coviro.2012.07.005.

Walker, P.G.T., Whittaker, C., Watson, O. et al. (2020). The global impact of COVID-19 and strategies for mitigation and suppression. Imperial College COVID-19 Response Team. https://doi.org/10.25561 177735

Wan, Y., Shang, J., Graham, R., Baric, R. S., \& Li, F. (2020). Receptor recognition by the novel coronavirus from Wuhan: an analysis based on decade-long structural studies of SARS coronavirus. Journal of Virology, 94(7), e00127-e220. https://doi.org/10.1128/JVI.00127-20.

Yang, C., Yang, X., \& Zhao, B. (2016). Person to person droplets transmission characteristics in unidirectional ventilated protective isolation room: the impact of initial droplet size. Building Simulation, 9 , 597-606. https://doi.org/10.1007/s12273-016-0290-7.

Zhang, J., Litvinova, M., Liang, Y., Wang, Y., Wang, W., \& Zhao, S. (2020). Changes in contact patterns shape the dynamics of the COVID-19 outbreak in China. Science. https://doi.org/10.1126/scien ce.abb8001. 
Zhang, T., Wu, Q., \& Zhang, Z. (2020). Probable Pangolin Origin of SARS-CoV-2 Associated with the COVID-19 Outbreak. Current biology: CB, 30 (7), 1346-1351.e2. https://doi.org/10.1016/j. cub.2020.03.022

Zhang, Y., Chen, C., Zhu, S. et al. (2020). Isolation of 2019-nCoV from a Stool Specimen of a LaboratoryConfirmed Case of the Coronavirus Disease 2019 (COVID-19). China CDC Weekly, 2(8): 123-124. https://doi.org/10.46234/ccdcw2020.033

Zhou, P., Yang, X. L., Wang, X. G., et al. (2020). A pneumonia outbreak associated with a new coronavirus of probable bat origin. Nature, 579(7798), 270-273. https://doi.org/10.1038/s41586-020-2012-7.

Zou, L., Ruan, F., Huang, M., et al. (2020). SARS-CoV-2 Viral load in upper respiratory specimens of infected patients. The New England Journal of Medicine, 382(12), 1177-1179. https://doi.org/10.1056/ NEJMc2001737.

Publisher's Note Springer Nature remains neutral with regard to jurisdictional claims in published maps and institutional affiliations.

\section{Affiliations}

\section{Satinder Kaur ${ }^{1} \cdot$ Hemant Bherwani ${ }^{2,3}$ (D) Sunil Gulia ${ }^{4} \cdot$ Ritesh Vijay $^{2} \cdot$ Rakesh Kumar $^{2}$}

1 CSIR-National Environmental Engineering Research Institute, Mumbai, Maharashtra 400018, India

2 CSIR-National Environmental Engineering Research Institute, Nagpur, Maharashtra 440020, India

3 Academy of Scientific and Innovative Research (AcSIR), Ghaziabad, Uttar Pradesh 201002, India

4 CSIR-National Environmental Engineering Research Institute, Delhi 110028, India 